\title{
Interdiffusion Between Zr Diffusion Barrier and U-Mo Alloy
}

\author{
K. Huang, Y. Park, D.D. Keiser Jr., and Y.H. Sohn
}

(Submitted April 16, 2012; in revised form June 19, 2012)

\begin{abstract}
U-Mo alloys are being developed as low-enrichment uranium fuels under the Reduced Enrichment for Research and Test Reactor (RERTR) program. Significant reactions have been observed between U-Mo fuels and Al or Al alloy matrix. Refractory metal $\mathrm{Zr}$ has been proposed as barrier material to reduce the interactions. In order to investigate the compatibility and barrier effects between U-Mo alloy and $\mathrm{Zr}$, solid-to-solid $\mathrm{U}$-10wt.\%Mo versus $\mathrm{Zr}$ diffusion couples were assembled and annealed at $600,700,800,900$, and $1000{ }^{\circ} \mathrm{C}$ for various times. The microstructures and concentration profiles due to interdiffusion and reactions were examined via scanning electron microscopy and electron probe microanalysis, respectively. Intermetallic phase $\mathrm{Mo}_{2} \mathrm{Zr}$ was found at the interface, and its population increased when annealing temperature decreased. Diffusion paths were also plotted on the U-Mo-Zr ternary phase diagrams with good consistency. The growth rate of interdiffusion zone between $\mathrm{U}-10 \mathrm{wt} . \% \mathrm{Mo}$ and $\mathrm{Zr}$ was also calculated under the assumption of parabolic diffusion and was determined to be about $10^{3}$ times lower than the growth rate of diffusional interaction layer found in diffusion couples $\mathrm{U}-10$ wt.\%Mo versus $\mathrm{Al}$ or $\mathrm{Al}-\mathrm{Si}$ alloy. Other desirable physical properties of $\mathrm{Zr}$ as barrier material, such as neutron adsorption rate, melting point, and thermal conductivity, are presented as supplementary information to demonstrate the great potential of $\mathrm{Zr}$ as the diffusion barrier for U-Mo fuel systems in RERTR.
\end{abstract}

Keywords diffusion barrier, diffusion couples, interdiffusion, metallic alloys, multicomponent diffusion, phase equilibria

\section{Introduction}

Uranium-molybdenum (U-Mo) dispersion and monolithic fuels in aluminum (Al) alloys are being developed as a low-enrichment metallic fuel system under the Reduced Enrichment for Research and Test Reactor (RERTR) program. ${ }^{[1-3]}$ Metallurgical interactions occur between the U-Mo fuels and Al alloy matrix during processing and irradiation due to interdiffusion. ${ }^{[4-6]}$ Efforts $^{[7-15]}$ have been made to document complex interactions and deleterious effects such as thinning of the cladding layer, formation of phases with poor irradiation behavior and relative low melting point, and thermal cracks.

Refractory metal $\mathrm{Zr}$ has been proposed as barrier layer between the U-Mo fuel and Al alloy matrix to reduce the interactions, since the diffusion of $\mathrm{U}$ in $\mathrm{Zr}$ is slow, ${ }^{[16-18]}$ and the fabrication of $\mathrm{Zr}$ barrier is compatible with the current hot-rolling techniques used by Idaho National Laboratory

K. Huang, Y. Park, and Y.H. Sohn, Department of Mechanical, Materials and Aerospace Engineering, Advanced Materials Processing and Analysis Center, University of Central Florida, Orlando, FL 32816, USA; and D.D. Keiser Jr., Nuclear Fuels and Materials Division, Idaho National Laboratory, Box 1625 Idaho Falls, ID 83415 , USA. Contact e-mail: Yongho.Sohn@ucf.edu.
(INL). ${ }^{[6]}$ Furthermore, interaction products that form between U-Mo fuel and $\mathrm{Zr}$ appear to be stable during irradiation. ${ }^{[19]}$ In an as-processed U-10wt.\%Mo monolithic fuel plate in AA6061 matrix with $\mathrm{Zr}$ diffusion barrier, ${ }^{[6]}$ multiple phases including $\alpha \mathrm{U}, \mathrm{Mo}_{2} \mathrm{Zr}$, $\mathrm{Zr}$ solid solution, $\gamma \mathrm{UZr}$, and $\mathrm{UZr}_{2}$ were observed at the interface of U-Mo with $\mathrm{Zr}$.

This study systematically investigated the interdiffusion and reaction between U-Mo alloy with $\mathrm{Zr}$, without the influence of multiple and complex hot-rolling process on the interfacial microstructure and phase constituents. Solid-tosolid isothermal diffusion method was used from 600 to $1000{ }^{\circ} \mathrm{C}$. The microstructure and concentration profiles of interdiffusion zone were examined by scanning electron microscopy (SEM) and electron probe microanalysis (EPMA), respectively. Diffusion paths at each temperature were determined and superimposed on the isothermal U$\mathrm{Mo}-\mathrm{Zr}$ ternary phase diagrams. The growth rate of interdiffusion zone was also calculated and compared to those of UMo versus $\mathrm{Al}$ and U-Mo versus Al-Si diffusion couples reported in the literature. ${ }^{[9,20]}$ Other desirable physical properties of $\mathrm{Zr}$ as barrier material are also presented.

\section{Experimental Procedure}

All metallographical preparation and assembly of diffusion couples were carried out under an argon (Ar) atmosphere inside a glove box to minimize oxidation of the U-Mo alloy and Zr. U-Mo rods were cast using high-purity depleted uranium (DU) and Mo via arc melting. They were melted three times to ensure homogeneity and then drop-cast to form 
Table 1 Temperature and time of diffusion anneal for U-10wt.\%Mo vs. Zr diffusion couples

\begin{tabular}{lc}
\hline Temperature, ${ }^{\circ} \mathbf{C}$ & Time, $\mathbf{h}$ \\
\hline 1000 & 96 \\
900 & 240 \\
800 & 480 \\
700 & 720 \\
600 & 960 \\
\hline
\end{tabular}

rods with $12.7 \mathrm{~mm}$ diameter. Zirconium rods of $99.99 \%$ purity (12.7 $\mathrm{mm}$ diameter) were acquired from a commercial source (Alpha-Aesar). The homogeneity in composition, phase constituents, and microstructure of the U-Mo and $\mathrm{Zr}$ were examined by $x$-ray diffraction (XRD; Rigaku DMAX-B) and scanning electron microscopy (SEM; Hitachi 3500N) equipped with $\mathrm{x}$-ray energy dispersive spectroscopy (XEDS).

Both the U-Mo alloy and Zr rods were sectioned into $3 \mathrm{~mm}$ thick disks, and the surfaces were metallographically polished down to $1 \mu \mathrm{m}$ using diamond paste. The prepared surfaces were then placed in contact with each other and held together by two clamping disks with stainless steel rods to form a jig. The jig assembly was wrapped in Ta foil, encapsulated in a quartz capsule, and sealed under an Ar atmosphere after repeated vacuum $\left(10^{-6} \mathrm{~Pa}\right)$ and $\mathrm{H}_{2}$ purge. The couples were annealed using a Lindberg/Blue three-zone tube furnace at the temperatures listed in Table 1. After annealing, the diffusion couples were quenched by breaking the quartz capsule in cold water. Each diffusion couple was then mounted in epoxy, cross-sectioned, and polished using $1 \mu \mathrm{m}$ diamond paste for microstructural examination and compositional analysis.

For each diffusion couple, SEM was performed to examine the interdiffusion microstructure. Electron probe microanalysis (JEOL Superprobe 733) was used to obtain the concentration profiles of $\mathrm{U}, \mathrm{Mo}$, and $\mathrm{Zr}$ from each couple using a point-to-point scan with a $5-10 \mu \mathrm{m}$ step size and an accelerating voltage of $20 \mathrm{keV}$. The pure metals, DU, $\mathrm{Zr}$, and Mo were used as standards. The intensities of the $\mathrm{U}-\mathrm{M}_{\alpha}, \mathrm{Zr}-\mathrm{L}_{\alpha}$, and Mo- $\mathrm{L}_{\alpha} \mathrm{x}$-rays were converted to compositions via $\mathrm{ZAF}$ correction.

\section{Results and Discussions}

\subsection{Composition of U-Mo Alloy}

The composition of U-Mo alloy was examined by EPMA at 10 random locations. Its average value and standard deviation were determined as reported in Table 2. The averaged composition, 20.91 at.\% Mo is very close to the target composition of U-10wt.\%Mo fuel, which is 21.61 at. $\%$ Mo. The standard deviation of the 10 measured points was 0.15 at.\%.

\subsection{Microstructure, Concentration Profiles, and Diffusion Paths}

Backscattered electron (BSE) micrographs and concentration profiles from the U-Mo versus $\mathrm{Zr}$ diffusion couples
Table 2 Composition of the starting U-Mo alloy determined by electron probe microanalysis

\begin{tabular}{lc}
\hline Point No. & Composition of Mo, at. $\%$ \\
\hline 1 & 20.82 \\
2 & 21.22 \\
3 & 20.89 \\
4 & 20.71 \\
5 & 20.74 \\
6 & 20.85 \\
7 & 21.01 \\
8 & 20.85 \\
9 & 20.96 \\
10 & 21.03 \\
Average composition & 20.91 \\
Standard deviation & 0.15 \\
\hline
\end{tabular}

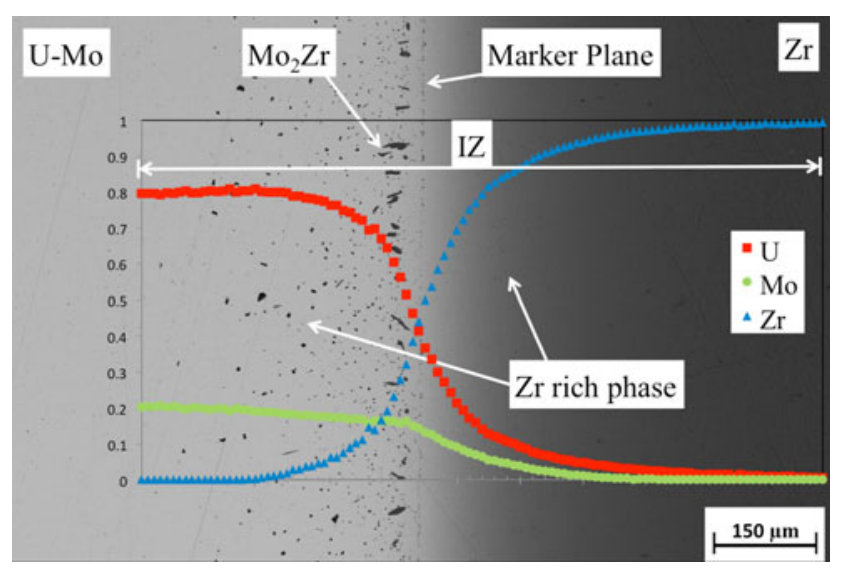

Fig. 1 Backscattered electron micrograph and concentration profiles from U-Mo vs. $\mathrm{Zr}$ diffusion couple annealed at $1000{ }^{\circ} \mathrm{C}$ for $96 \mathrm{~h}$

annealed at $1000,900,800$, and $700{ }^{\circ} \mathrm{C}$ are presented in Fig. 1 to 4 . Figure 5 shows the interfacial microstructure developed at $600{ }^{\circ} \mathrm{C}$ where the couple had a negligible interaction. The large dark precipitates near the interface in Fig. 1 to 4 were identified as $\mathrm{Mo}_{2} \mathrm{Zr}$ using semiquantitative composition analysis by XEDS and the Mo- $\mathrm{Zr}$ equilibrium binary phase diagram presented in Fig. $6 .{ }^{[21]}$ When the diffusion anneal temperature decreased from 1000 to $700{ }^{\circ} \mathrm{C}$, the population of the $\mathrm{Mo}_{2} \mathrm{Zr}$ precipitates increased (i.e., an increase in volume fraction of $\mathrm{Mo}_{2} \mathrm{Zr}$ ). The U-Mo versus $\mathrm{Zr}$ ternary diffusion couples examined in this study have the extra degree of freedom based on Gibbs phase rule that allows the development of two-phase layer that includes $\mathrm{Mo}_{2} \mathrm{Zr}$ phase. Small dark precipitates present throughout the U-Mo alloy are identified as Zr-rich phase, which is composed of $>95$ at. $\% \mathrm{Zr}$ and a few at.\% of $\mathrm{U}$ and Mo. This tiny Zr-rich precipitate should be the $\alpha \mathrm{Zr}$, formed during quenching. The U-Zr solid solution eutectoidally decomposed into $\alpha \mathrm{Zr}$ and $\mathrm{Mo}_{2} \mathrm{Zr}$ upon cooling according to the U-Zr phase diagram shown in Fig. 7. ${ }^{[21]}$ Unfortunately, 


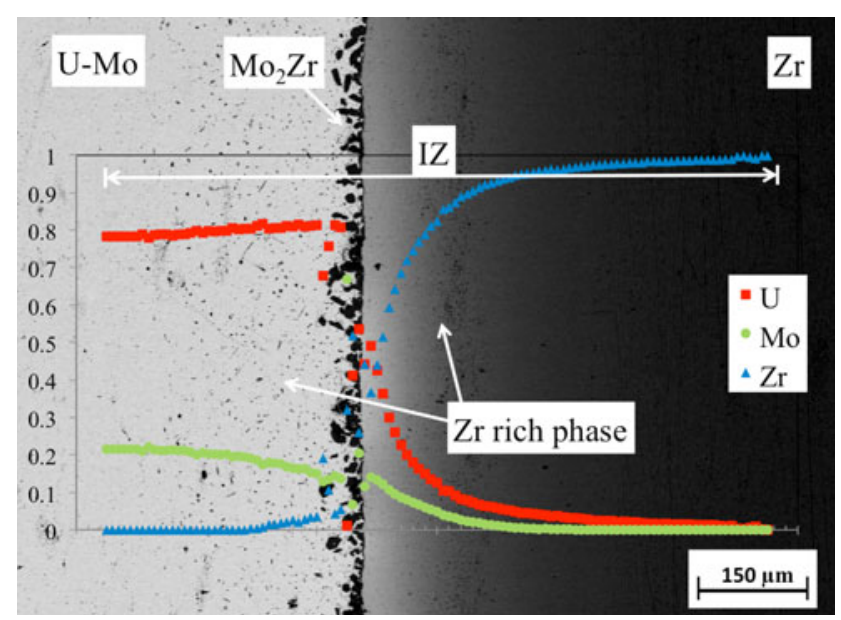

Fig. 2 Backscattered electron micrograph and concentration profiles from U-Mo vs. $\mathrm{Zr}$ diffusion couple annealed at $900{ }^{\circ} \mathrm{C}$ for $240 \mathrm{~h}$

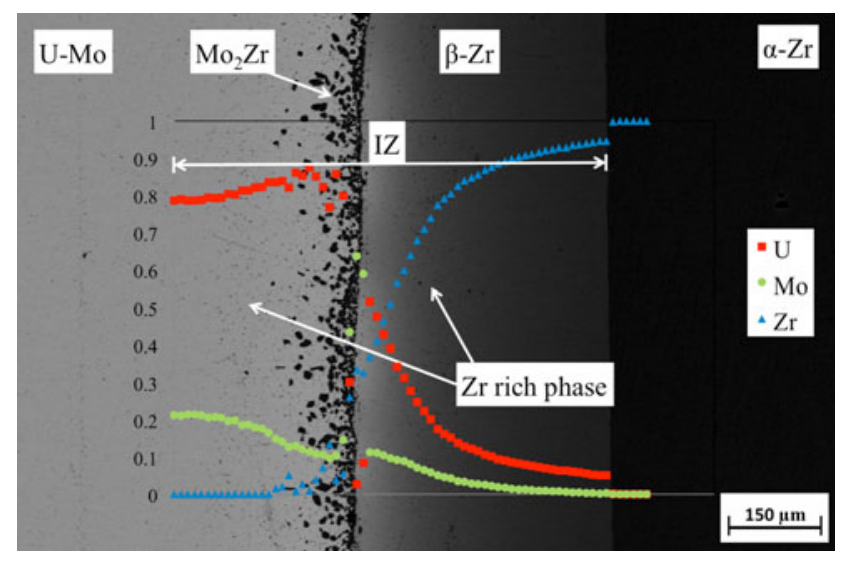

Fig. 3 Backscattered electron micrograph and concentration profiles from U-Mo vs. $\mathrm{Zr}$ diffusion couple annealed at $800{ }^{\circ} \mathrm{C}$ for $480 \mathrm{~h}$

the $\alpha \mathrm{Zr}$ precipitates are too small in size, and the eutectoid structure cannot be observed clearly.

Concentration profiles determined by EPMA show an uphill diffusion of $\mathrm{U}$ on the $\mathrm{U}-\mathrm{Mo}$ side. Scatter in concentration profiles is observed near the interface because of the $\mathrm{Mo}_{2} \mathrm{Zr}$ precipitates. When diffusion anneal temperature decreased to $600{ }^{\circ} \mathrm{C}$, U-Mo and $\mathrm{Zr}$ diffusion couple exhibited a negligible interaction despite the $960 \mathrm{~h}$ of diffusion anneal. A very small intermediate phase with thickness of about 1-2 $\mu \mathrm{m}$ was observed discretely at the interface as seen in Fig. 5. The composition of these intermediate phases has not been determined accurately since the size is too small.

There is an allotropic transformation between $\alpha \mathrm{Zr}$ and $\beta Z r$ at $863{ }^{\circ} \mathrm{C}$ according to $\mathrm{U}-\mathrm{Zr}$ phase diagram shown in Fig. 7. ${ }^{[21]}$ Therefore, both $\alpha \mathrm{Zr}$ and $\beta \mathrm{Zr}$ exist on the $\mathrm{Zr}$ side at 800 and $700{ }^{\circ} \mathrm{C}$ as shown in Fig. 3 and 4 , while only $\beta \mathrm{Zr}$ exists at 1000 and $900{ }^{\circ} \mathrm{C}$ as shown in Fig. 1 and 2. A

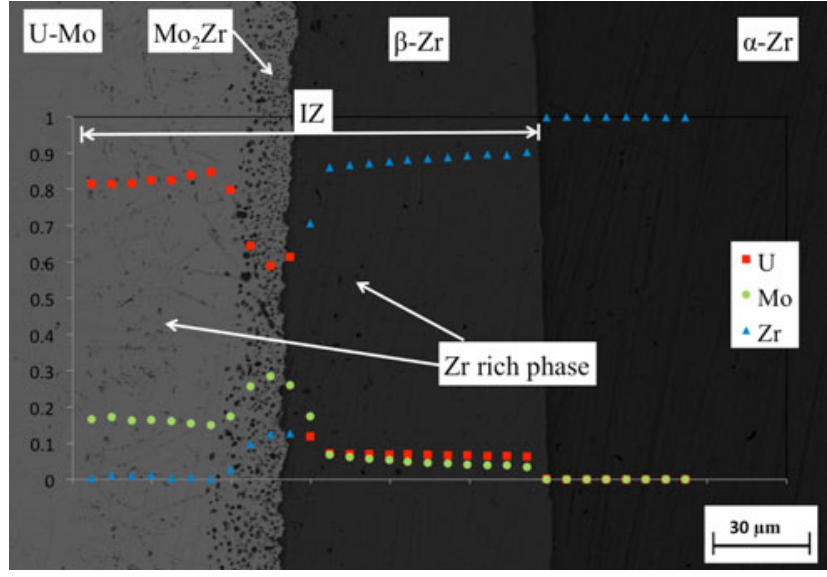

Fig. 4 Backscattered electron micrograph and concentration profiles from U-Mo vs. $\mathrm{Zr}$ diffusion couple annealed at $700^{\circ} \mathrm{C}$ for $720 \mathrm{~h}$

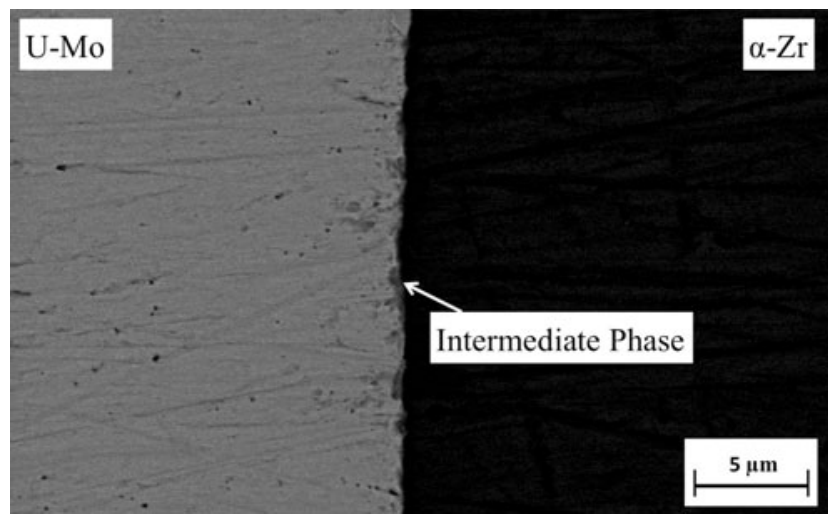

Fig. 5 Backscattered electron micrograph from U-Mo vs. $\mathrm{Zr}$ diffusion couple annealed at $600{ }^{\circ} \mathrm{C}$ for $960 \mathrm{~h}$

marker plane was clearly observed in diffusion couple annealed at $1000{ }^{\circ} \mathrm{C}$ as marked in Fig. 1. However, unfortunately, markers could not be identified in other diffusion couples.

U-Mo-Zr ternary phase diagrams have been determined by Ivanov and Bagrov for isothermal temperature of 500, $575,600,625,650,675,700,750$, and $1000{ }^{\circ} \mathrm{C}{ }^{[22,23]}$ The concentration profiles of diffusion couples were plotted as diffusion paths on U-Mo-Zr ternary phase diagrams shown in Fig. 8. Since there is no available ternary phase diagram at 900 and $800{ }^{\circ} \mathrm{C}$, the diffusion paths are presented on the isotherms at 1000 and $750{ }^{\circ} \mathrm{C}$, respectively. Solid circles fitted with solid lines in Fig. 8 present the composition measured by EPMA in single-phase regions. The experimental data within the two-phase region with $\mathrm{Mo}_{2} \mathrm{Zr}$ precipitates had scatters in composition. Therefore, diffusion path in two-phase region is estimated based on average composition by considering the composition and volume fraction of $\mathrm{U}-\mathrm{Zr}$ solid solution and precipitates, which is shown as dot line in Fig. 8. In general, the diffusion paths 


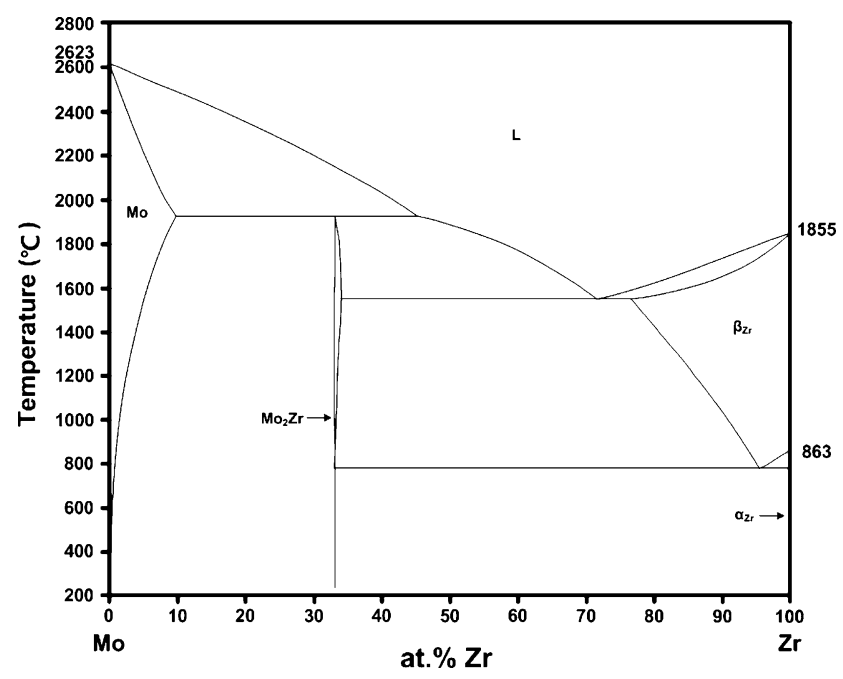

Fig. 6 Equilibrium binary phase diagram of Mo-Zr system ${ }^{[21]}$

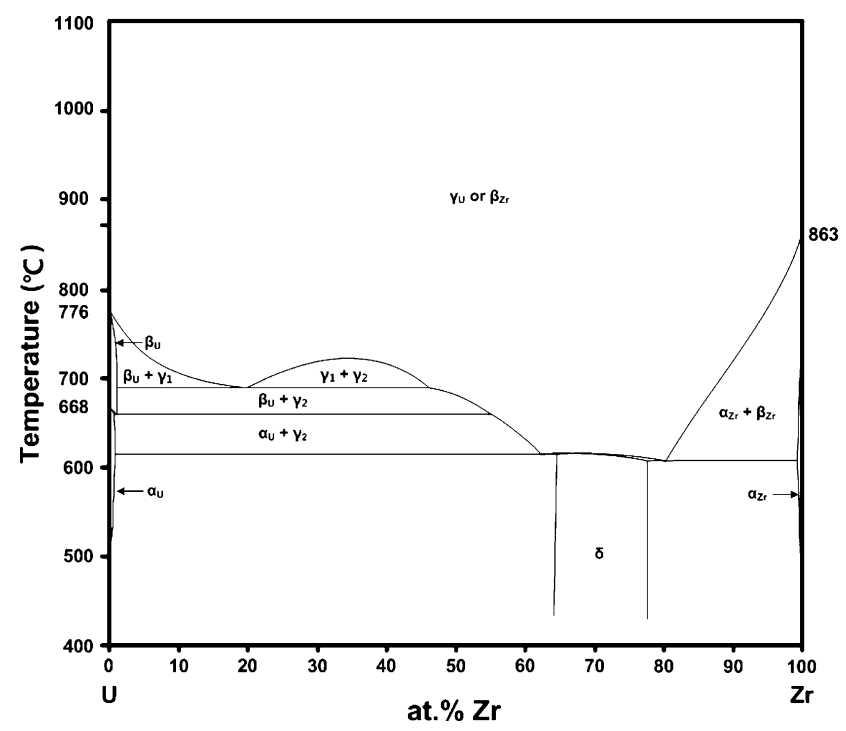

Fig. 7 Equilibrium binary phase diagram of U-Zr system ${ }^{[21]}$

constructed based on EMPA measurement were consistent with the ternary phase diagrams determined by Ivanov and Bagrov. ${ }^{[22,23]}$

Based on the shape of the diffusion paths and concentration profiles, it is clear that $\mathrm{Zr}$ diffuses slowly on the UMo alloy side, and Mo is the slow-moving specie on the $\mathrm{Zr}$ side. On the U-Mo alloy side, gradients of concentration for Mo and $U$ develop even without a significant diffusional penetration of $\mathrm{Zr}$ as shown in Fig. 1 to 4 . This is also reflected on the diffusion paths in Fig. 8 wherein the diffusion paths take off toward the pure U corner. While the Mo moves down the concentration gradient, $U$ moves up toward higher $\mathrm{U}$ concentration. This result suggests that $\mathrm{Zr}$ is an excellent diffusion barrier to retain the high U-density in the U-Mo fuel. With an increase in $\mathrm{Zr}$ concentration, diffusion path enters the two-phase $\left(\mathrm{Mo}_{2} \mathrm{Zr}\right.$ and $\left.\gamma-\mathrm{U}\right)$ region.
This is consistent with the observation that $\mathrm{Mo}_{2} \mathrm{Zr}$ precipitates in $\gamma$-matrix exist at the interface. The U-Mo- $\mathrm{Zr}$ isotherms in Fig. 8 clearly show that a decrease in the temperature from 1000 to $700{ }^{\circ} \mathrm{C}$ reduces the $\mathrm{U}-\mathrm{Zr}$ solidsolution phase field and expands the two-phase $\left(\mathrm{Mo}_{2} \mathrm{Zr}\right.$ and $\gamma \mathrm{U})$ field. Correspondingly, the volume fraction of $\mathrm{Mo}_{2} \mathrm{Zr}$ increased as shown in Fig. 1 to 4.

Toward the $\mathrm{Zr}$ end, diffusion path passes through the $\mathrm{U}-\mathrm{Zr}$ solid solution and ends at pure $\beta \mathrm{Zr}$ at higher temperatures of 1000 and $900{ }^{\circ} \mathrm{C}$, as presented in Fig. 8(a) and (b). At 800 and $700{ }^{\circ} \mathrm{C}$, the diffusion path goes through $\mathrm{U}-\mathrm{Zr}$ solid solution and jumps into $\alpha \mathrm{Zr}$ with negligible solubility for either $U$ or Mo as presented in Fig. 8(c) and (d). The diffusion paths within the $\beta \mathrm{Zr}$, for example at 1000 and $900{ }^{\circ} \mathrm{C}$, take off from pure $\mathrm{Zr}$ toward the U-corner of the isotherm and suggest that Mo is the slow-moving specie in the $\beta \mathrm{Zr}$ solid solution. Presence of Mo plays a significant role on the diffusion path and solubility of $\mathrm{Zr}$ in $\mathrm{U}-\mathrm{Zr}$ solid solution, especially at $700{ }^{\circ} \mathrm{C}$. Based on the $\mathrm{U}-\mathrm{Zr}$ binary phase diagram shown in Fig. 7 , the solubility range of $\mathrm{Zr}$ in $\mathrm{U}-\mathrm{Zr}$ solid at $700{ }^{\circ} \mathrm{C}$ should be $50-87$ at.\%. However, the addition of Mo changes the shape of diffusion paths dramatically and alters the diffusion paths to pass just a small U-Zr solid-solution region as shown in Fig. 8(d). This causes the solubility range of $\mathrm{Zr}$ in the $\mathrm{U}-\mathrm{Zr}$ solid solution to be much smaller, which is $85-90$ at.\%.

\subsection{Growth Rate of Interdiffusion Zone}

For $\mathrm{Zr}$ to be an effective diffusion barrier between U-Mo fuel and Al matrix, the overall magnitude of diffusional interaction must be small. Figure 5 shows that negligible interdiffusion was observed even after $960 \mathrm{~h}$ of isothermal anneal at $600{ }^{\circ} \mathrm{C}$. To compare and contrast the interdiffusion behavior of diffusion couples U-Mo versus $\mathrm{Zr}$ to U-Mo versus $\mathrm{Al}$ (or Al-Si alloy), parabolic growth rate, $K$, of interdiffusion zone was calculated at 1000,900 , and $800{ }^{\circ} \mathrm{C}$. Thickness of interdiffusion zone (IZ) is simply defined as the distance between U-10wt.\%Mo and pure $\mathrm{Zr}$ where concentration gradient becomes negligible (terminal ends where $\partial C / \partial x=0)$. Growth rates of interdiffusion zone were calculated by assuming $K=(\Delta x)^{2} / 2 t$, where, $\Delta x$ is the thickness of IZ, and they are reported in Table 3 for 1000, 900 , and $800{ }^{\circ} \mathrm{C}$.

Figure 9 shows that the temperature dependence of the IZ growth rate, $K$, obeys the Arrhenius relation in the temperature range from 800 to $1000{ }^{\circ} \mathrm{C}$ very well. The pre-exponential factor, $K_{\mathrm{o}}$, and activation energy, $Q_{\mathrm{K}}$, of the growth rate were determined and are also reported in Table 3. Growth rates at 700,600 , and $500{ }^{\circ} \mathrm{C}$ were then calculated following simple Arrhenius extrapolation as reported in Table 3 and presented in Fig. 9. Table 4 lists the growth rate determined from diffusion couples, U-Mo versus $\mathrm{Al}$ and U-Mo versus Al-Si, examined by Perez et al. ${ }^{[9,20]}$ The growth rate was calculated from the thickness of the complex intermetallic layer. Tables 3 and 4 demonstrate that the growth rates of interdiffusion zone between U-10wt.\%Mo and $\mathrm{Zr}$ is $2-3$ orders of magnitude slower than those between U-10wt.\%Mo and $\mathrm{Al}$ or $\mathrm{Al}-\mathrm{Si}$ alloys. 


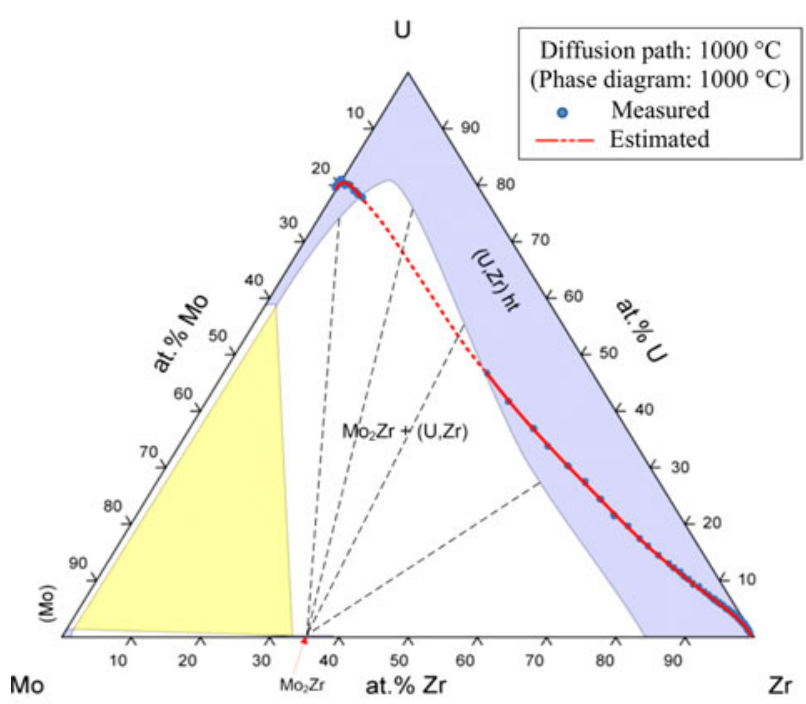

(a)

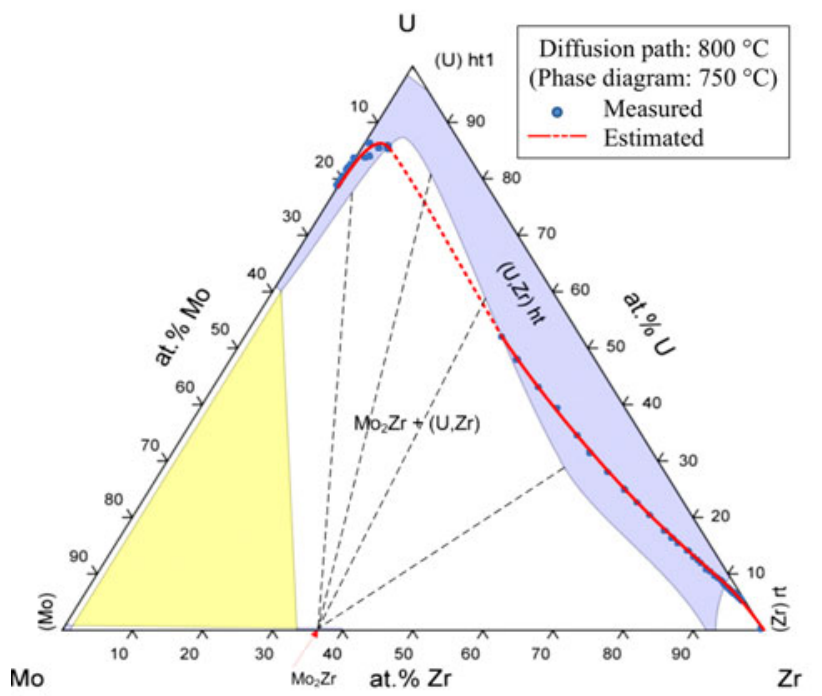

(c)

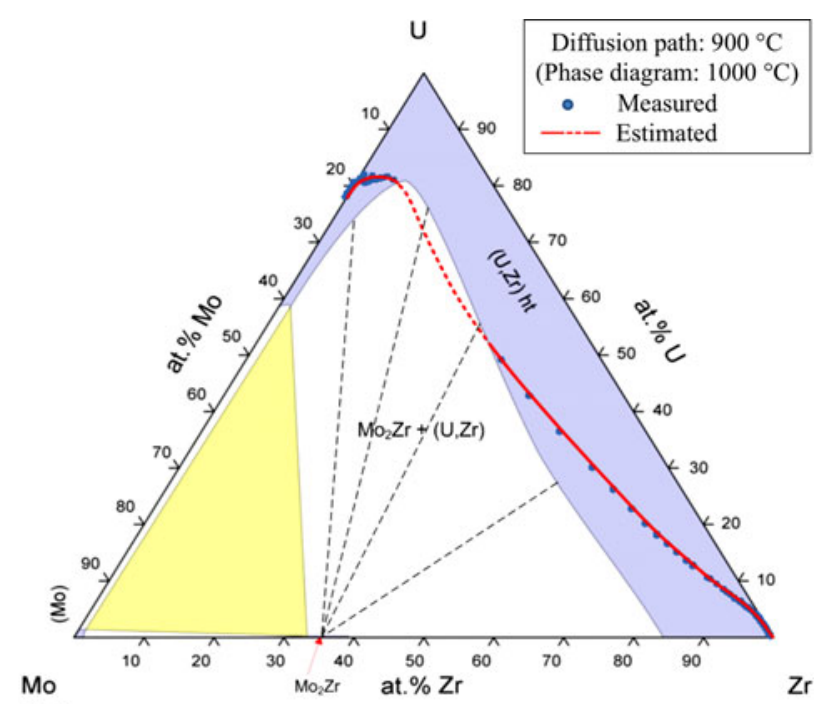

(b)

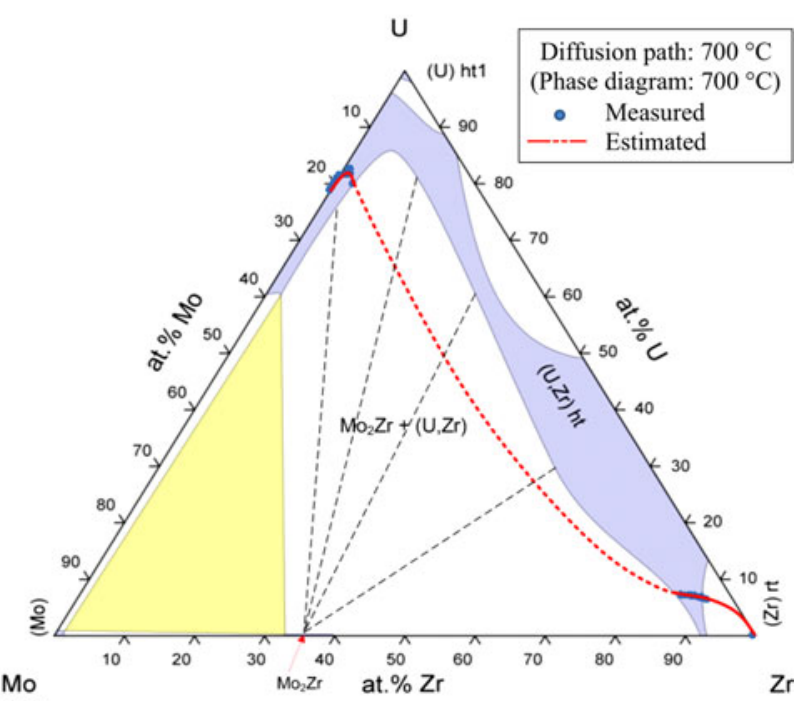

(d)

Fig. 8 Diffusion path from U-Mo vs. Zr diffusion couple annealed at (a) $1000{ }^{\circ} \mathrm{C}$ for $96 \mathrm{~h}$, (b) $900{ }^{\circ} \mathrm{C}$ for $240 \mathrm{~h}$, (c) $800{ }^{\circ} \mathrm{C}$ for $480 \mathrm{~h}$, and (d) $700{ }^{\circ} \mathrm{C}$ for $720 \mathrm{~h}$. The experimental data measured by EMPA in single phase are presented as solid circles. Solid and dashed lines represent diffusion path determined in single-phase region and estimated in two-phase region, respectively

Table 3 Growth rate of interdiffusion zone determined from the U-10wt.\%Mo vs. $\mathrm{Zr}$ diffusion couples

\begin{tabular}{|c|c|c|c|c|c|}
\hline Temperature, ${ }^{\circ} \mathrm{C}$ & Thickness of IZ, $\mu \mathrm{m}$ & Annealing time, $h$ & Growth rate $(K), \mathbf{m}^{2} / \mathbf{s}$ & $\tilde{D}_{\mathbf{0}}, \mathbf{m}^{2} / \mathbf{s}$ & $Q_{\mathrm{K}}, \mathrm{kJ} / \mathrm{mol}$ \\
\hline \multicolumn{6}{|l|}{ Measured } \\
\hline 1000 & 1130 & 96 & $1.85 \times 10^{-12}$ & & \\
\hline 900 & 990 & 240 & $5.67 \times 10^{-13}$ & & \\
\hline 800 & 650 & 480 & $1.22 \times 10^{-13}$ & $7.95 \times 10^{-05}$ & 183.83 \\
\hline \multicolumn{6}{|l|}{ Calculated } \\
\hline 700 & $\ldots$ & $\ldots$ & $2.10 \times 10^{-14}$ & & \\
\hline 600 & $\ldots$ & $\ldots$ & $2.36 \times 10^{-15}$ & & \\
\hline 500 & $\ldots$ & $\ldots$ & $1.51 \times 10^{-16}$ & & \\
\hline
\end{tabular}




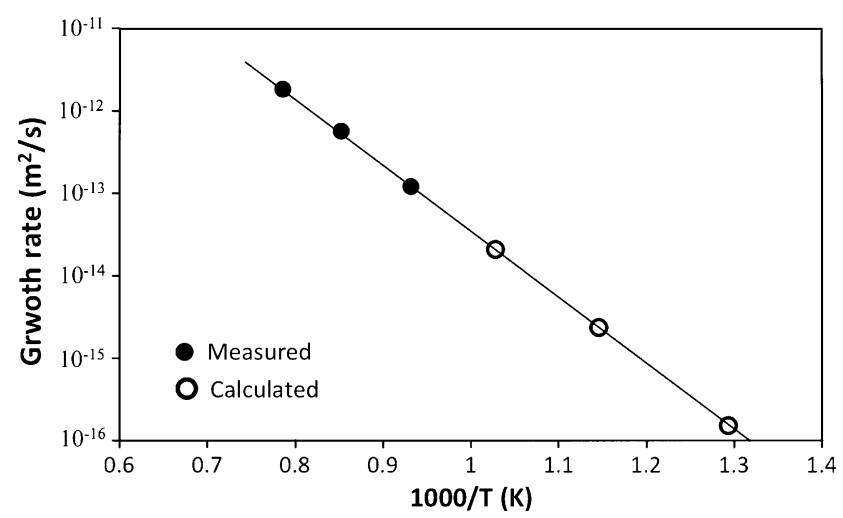

Fig. 9 Arrhenius temperature dependence of growth rate for interdiffusion zone found in the diffusion couples, U-Mo vs. Zr. The measured growth rate at 800,900 , and $1000{ }^{\circ} \mathrm{C}$ and calculated values at 500,600, and $700{ }^{\circ} \mathrm{C}$ are represented by solid and empty circles, respectively

Table 4 Growth rate of interdiffusion zone in U-Mo vs. Al and U-Mo vs. Al-Si diffusion couples ${ }^{[9,20]}$

\begin{tabular}{lcc}
\hline Diffusion couple & $\begin{array}{c}\text { Annealing } \\
\text { temperature, }{ }^{\circ} \mathbf{C}\end{array}$ & $\begin{array}{c}\text { Growth rate (K)} \\
\mathbf{m}^{2} / \mathbf{s}\end{array}$ \\
\hline U-7wt.\%Mo vs. Al & 600 & $4.05 \times 10^{-13}$ \\
U-10wt.\%Mo vs. Al & 600 & $1.69 \times 10^{-12}$ \\
U-12wt.\%Mo vs. Al & 600 & $7.20 \times 10^{-13}$ \\
U-10wt.\%Mo vs. Al-2wt.\%Si & 550 & $1.45 \times 10^{-14}$ \\
U-10wt.\%Mo vs. Al-5wt.\%Si & 550 & $1.62 \times 10^{-14}$ \\
\hline
\end{tabular}

\subsection{Other Desirable Barrier Properties of Zr}

The ideal barrier materials for metallic fuel system require:

Interdiffusion or reactions between barriers and metallic fuels should be slow.

No or insignificant amount of intermetallic phases should form for better structural integrity. Thermal expansion coefficients and other thermomechanical properties of intermetallic phases may vary significantly. Solid solution is preferred because relevant properties would vary gradually with composition.

Intermetallic phases, if formed due to interdiffusion and reaction, should be stable under irradiation.

Melting point should be high.

Neutron adsorption rate should be low.

Thermal conductivity should be high.

Corrosion resistant should be good.

Results from this study demonstrate that diffusional interaction between U-Mo and $\mathrm{Zr}$ is slow compared to U-Mo and $\mathrm{Al}$ or $\mathrm{Al}-\mathrm{Si}$ alloys. For the temperature range investigated in this study, only one intermetallic phase $\mathrm{Mo}_{2} \mathrm{Zr}$ exists as precipitates near the interface. However, at the lower temperature, other intermetallic or solid-solution phases may form according to the U-Mo-Zr ternary phase diagram, ${ }^{[23]}$ such as, $\mathrm{UZr}_{2}, \mathrm{U}_{4} \mathrm{Zr}_{5} \mathrm{Mo}, \mathrm{U}_{6} \mathrm{Zr}_{3} \mathrm{Mo}$, and $\mathrm{U}_{2} \mathrm{Mo}$. In Perez's study ${ }^{[6]}$ multiple phases including $\alpha \mathrm{U}, \mathrm{Mo}_{2} \mathrm{Zr}, \mathrm{U}-\mathrm{Zr}$ solid solution, and $\mathrm{UZr}_{2}$ were observed at the interface between U-Mo with $\mathrm{Zr}$ in the hot-rolled and annealed U-Mo fuel with $\mathrm{Zr}$ as barrier. Therefore, a further investigation of phase equilibrium and diffusional interaction at lower temperature would be required. However, Robinson ${ }^{[19]}$ has reported that the interaction products containing $\mathrm{Zr}$ appear to be stable during irradiation.

As a refractory metal, $\mathrm{Zr}$ has a very high melting temperature of $1855{ }^{\circ} \mathrm{C}$, and high thermal conductivity of $22.6 \mathrm{~W} / \mathrm{m} \cdot \mathrm{K} \cdot{ }^{[21]}$ The neutron absorption rate of $\mathrm{Zr}$ is fairly low. The cross section for $2200 \mathrm{~m} / \mathrm{s}$ neutrons of $\mathrm{Zr}$ is 0.185 barn, which is one of the lowest among naturally occurring metals. ${ }^{[24]}$ Moreover, $\mathrm{Zr}$ is highly resistant to corrosion by alkalis, acids, salt water, and other agents. ${ }^{[25]}$ Diffusional interaction between $\mathrm{Zr}$ and $\mathrm{Al}$ has been studied by Kidson et al. ${ }^{[26]}$ and Laik et al. ${ }^{[27]}$ However, there is discrepancy on the formation and growth rates of intermetallic phases between the two studies. Further investigation into this discrepancy needs to be conducted.

\section{Summary}

Diffusional interaction between U-10wt.\%Mo alloy and Zr has been systematically studied in the temperature range of 600 to $1000{ }^{\circ} \mathrm{C} . \mathrm{Mo}_{2} \mathrm{Zr}$ has been found at the interface, and its population increased with a decrease in the temperature of diffusion anneal. The diffusion paths were plotted on U-Mo$\mathrm{Zr}$ ternary isotherms and examined with respect to ternary diffusional interactions. The growth rates of interdiffusion zone between U-10wt.\%Mo and $\mathrm{Zr}$ were found to be about $10^{3}$ times slower than those between U-10wt.\%Mo and $\mathrm{Al}$ or Al-Si alloys. Other desirable factors of $\mathrm{Zr}$ working as barrier material were also presented.

\section{Acknowledgments}

This work was supported by the U.S. Department of Energy, Office of Nuclear Materials Threat Reduction (NA212), National Nuclear Security Administration, under DOE-NE Idaho Operations Office Contract DE-AC0705ID14517. Accordingly, the U.S. Government retains a nonexclusive, royalty-free license to publish or reproduce the published form of this contribution or to allow others to do so, for U.S. Government purposes.

\section{References}

1. D. Keiser, S. Hayes, M. Meyer, and C. Clark, High-Density, Low-Enriched Uranium Fuel for Nuclear Research Reactors, $J O M, 2003$, 55, p 55-58

2. J.L. Snelgrove, G.L. Hofman, M.K. Meyer, C.L. Trybus, and T.C. Wiencek, Development of Very-High-Density Low-Enriched-Uranium Fuels, Nucl. Eng. Des., 1997, 178, p 119-126 
3. D. Wachs, D. Keiser, M. Meyer, D. Burkes, C. Clark, G. Moore, J.-F. Jue, T. Totev, G. Hofman, T. Wiencek, Y.S. Kim, and J. Snelgrove, High Density Fuel Development for Research Reactors. Glob. 2007 Adv. Nucl. Fuel Cycles Syst., 2007

4. M.K. Meyer, G.L. Hofman, S.L. Hayes, C.R. Clark, T.C. Wiencek, J.L. Snelgrove, R.V. Strain, and K.H. Kim, LowTemperature Irradiation Behavior of Uranium-Molybdenum Alloy Dispersion Fuel, J. Nucl. Mater., 2002, 304, p 221-236

5. A. Leenaers, S. Van den Berghe, E. Koonen, C. Jarousse, F. Huet, M. Trotabas, M. Boyard, S. Guillot, L. Sannen, and M. Verwerft, Post-Irradiation Examination of Uranium-7 wt $\%$ Molybdenum Atomized Dispersion Fuel, J. Nucl. Mater., 2004, 335, p 39-47

6. E. Perez, B. Yao, D.D. Keiser, and Y.H. Sohn, Microstructural Analysis of As-Processed U-10 wt.\%Mo Monolithic Fuel Plate in AA6061 Matrix with Zr Diffusion Barrier, J. Nucl. Mater., 2010, 402, p 8-14

7. D.D. Keiser, J.F. Jue, B. Yao, E. Perez, Y. Sohn, and C.R. Clark, Microstructural characterization of U-7Mo/Al-Si alloy matrix dispersion fuel plates fabricated at $500 \mathrm{C}, \mathrm{J}$. Nucl. Mater., 2011, 412, p 90-99

8. B. Yao, E. Perez, D.D. Keiser, Jr., J.-F. Jue, C.R. Clark, N. Woolstenhulme, and Y. Sohn, Microstructure Characterization of As-Fabricated and $475 \mathrm{C}$ Annealed U-7 wt.\% Mo Dispersion Fuel in Al-Si Alloy Matrix, J. Alloys Compd., 2011, 509, p 9487-9496

9. E. Perez, D. Keiser, and Y. Sohn, Phase Constituents and Microstructure of Interaction Layer Formed in U-Mo Alloys vs Al Diffusion Couples Annealed at 873 K (600 C), Metall. Mater. Trans. A, 2011, 42, p 3071-3083

10. A. Leenaers, S. Van den Berghe, W. Van Renterghem, F. Charollais, P. Lemoine, C. Jarousse, A. Rohrmoser, and W. Petry, Irradiation Behavior of Ground U(Mo) Fuel with and Without Si Added to the Matrix, J. Nucl. Mater., 2011, 412, p 41-52

11. X. Liu, T.C. Lu, Z.H. Xing, and D.Z. Qian, Effects of Different Irradiation Conditions on Swelling Performance of U(10)MoAl Dispersion Fuel, Rare Metal Mater. Eng., 2011, 40, p 1125

12. F. Mazaudier, C. Proye, and F. Hodaj, Further Insight into Mechanisms of Solid-State Interactions in UMo/Al System, $J$. Nucl. Mater, 2008, 377, p 476-485

13. C. Komar Varela, M. Mirandou, S. Aricó, S. Balar, and L. Gribaudo, Interdiffusion Between U(Mo, Pt) or U(Mo, Zr) and Al or Al A356 Alloy, J. Nucl. Mater., 2009, 395, p 162-168
14. Y. Kim, G. Hofman, H. Ryu, and S. Hayes, IrradiationEnhanced Interdiffusion in the Diffusion Zone of U-Mo Dispersion Fuel in A1, J. Phase Equilib. Diffus., 2006, 27, p 614-621

15. H. Ryu, J. Park, C. Kim, Y. Kim, and G. Hofman, Diffusion Reaction Behaviors of U-Mo/Al Dispersion Fuel, J. Phase Equilib. Diffus., 2006, 27, p 651-658

16. L. Pavlinov, A. Nakonechnikov, and V. Bykov, Diffusion of Uranium in Molybdenum, Niobium, Zirconium, and Titanium, Sov. At. Energy, 1965, 19, p 1495-1497

17. G.B. Fedorov, E.A. Smirnov, F.I. Zhomov, V.N. Gusev, and S.A. Paraev, Diffuion of Uranium in Refractory Body-Center-Cubic Metals, At. Energy, 1971, 31, p 1280-1282

18. T. Ogata, M. Akabori, A. Itoh, and T. Ogawa, Interdiffusion in Uranium-Zirconium Solid Solutions, J. Nucl. Mater., 1996, 232, p 125-130

19. A.B. Robinson, D.M. Wachs, D.E. Burkes, and D.D. Keiser, US RERTR Fuel Development Post Irradiation Examination Results, Proceedings of the 30th International Meeting on Reduced Enrichment for Research and Test Reactors (RERTR), Washington, DC, 2008

20. E. Perez, D.D. Keiser, Jr., B. Yao, and Y.H. Sohn, Interdiffusion in Diffusion Couples: U-Mo vs Al and Al-Si, RERTR 2009 31st International Meeting on Reduced Enrichment for Research and Test Reactors (RERTR), Beijing, China, 2009

21. E.A. Brandes and G.B. Brook, Smithells Metals Reference Book, 1992

22. O.S. Ivanov and G.N. Bagrov, Isothermal Cross Sections of the Triple System Uranium-Molybdenum-Zirconium at $1000{ }^{\circ} \mathrm{C}-625{ }^{\circ} \mathrm{C}$, Struct. Alloys Certain Syst. Cont. Uranium Thorium, 1963, p 131-153

23. O.S. Ivanov and G.N. Bagrov, Isothermal Cross Sections at $600{ }^{\circ} \mathrm{C}, 575{ }^{\circ} \mathrm{C}$, and $500{ }^{\circ} \mathrm{C}$, Polythermal Sections, and the Phase Diagram of the Triple System Uranium-MolybdenumZirconium, Struct. Alloys Certain Syst. Cont. Uranium Thorium, 1963, p 154-176

24. V.F. Sears, Neutron Scattering Lengths and Cross Sections, Neutron News, 1992, 3, p 26-37

25. J.R. Davis, Properties and Selection: Nonferrous Alloys and Special-Purpose Materials, Vol 2, ASM Handbook, 1992

26. G.V. Kidson and G.D. Miller, A Study of the Interdiffusion of Aluminum and Zirconium, J. Nucl. Mater., 1964, 12, p 61-69

27. A. Laik, K. Bhanumurthy, and G.B. Kale, Intermetallics in the Zr-Al Diffusion Zone, Intermetallics, 2004, 12, p 69-74 